\title{
O lugar da cultura. A cultura do lugar
}

\section{El lugar de la cultura. La cultura del lugar}

\section{The place of the the culture. The culture of the place}

\author{
Luiz Augusto F. Rodrigues ${ }^{1}$
}

\section{Palavras chave:}

Cultura e imaginário

Apropriação do espaço

Lugar antropológico

\section{Resumo:}

Este artigo foca a cultura em sua dimensão contemporânea, explorando a noção de diversidade cultural e contrapondo-a à persistência de certa padronização de valores. Discute referências ao planejamento urbano estratégico que tende a produzir o esvaziamento simbólico dos lugares. Nesta perspectiva, discute noções como lugar antropológico $X$ lugar cenográfico/espetacular. Busca focar a questão do território em sua dimensão antropológica (das práticas), em sua dimensão geográfica (espaço apropriado e subjetivado) e em sua dimensão urbanística (a produção do espaço $X$ recepção e apropriação), com o intuito de discutir as correlações cultura / identidade / sociabilidade / apropriação do território. 


\section{Resumen:}

Este artículo se centra en la cultura en su dimensión contemporánea, explorando la noción de diversidad cultural y oponiéndola a la persistencia de cierta estandarización de valores. Discute referencias al planeamiento urbano estratégico que tiende a producir el vaciamiento simbólico de los lugares. En esta perspectiva, discute temáticas como lugar antropológico X lugar escenográfico/espectacular. Busca enfocar la cuestión del territorio en su dimensión antropológica (de las prácticas), en su dimensión geográfica (espacio apropiado y subjetivado) y en su dimensión urbanística (la producción del espacio $X$ recepción y apropiación), con la intención de discutir las correlaciones cultura / identidad / sociabilidad / apropiación del territorio.
Palabras clave:

Cultura y imaginario

Apropiación del espacio

Lugar antropológico

\section{Keywords:}

Culture and imaginary

Appropriation of space

Anthropological place

\section{Abstract:}

This article focuses on the culture in its contemporary dimension, exploring the notion of cultural diversity and opposing it to the persistence of a certain standardization of values. It discusses references to the strategic urban planning that tends to produce the symbolic emptying of the places. In this perspective, it discusses notions such as anthropological place $X$ scenographic/spectacular place. It aims to focus on the question of the territory in its anthropological dimension (the practices), in its geographical dimension (appropriated and subjective space) and in its urbanistic dimension (the production of the space $X$ reception and appropriation), intending to discuss the correlations culture / identity / sociability / appropriation of the territory. 


\section{O lugar da cultura. A cultura do lugar}

Até pouco tempo atrás a cultura atendeu a modos ideológicos que procuravam reproduzir ideias de subalternidade e atraso. Os ideais iluministas, por exemplo, perpetuaram tais entendimentos: cultura letrada, cultura superior, erudição cultural, cultura como reflexo de condições materiais ligadas ao conhecimento científico e ao domínio de determinadas linguagens artísticas. $E$ isso até pouco tempo atrás mesmo. A "superação" (??) dessa noção de cultura e sua substituição pela valorização da diversidade cultural dos povos e de suas práticas antropológicas é fato recente. Data, por exemplo, de 1995 as preocupações da UNESCO com a valorização da diversidade de modos culturais presentes no mundo. ${ }^{2}$

Essa nova perspectiva abre espaço para a percepção e reconhecimento das práticas culturais como processos definidores das subjetividades dos indivíduos e grupos. Imagem e reflexo. Forma e conteúdo. Expressão simbólica e referência imaginária. Como aponta Slavoj Zizek (1996, p. 323):

A ideologia [...] é uma construção de fantasia que serve de esteio à nossa própria "realidade": uma "ilusão" que estrutura nossas relações sociais reais e efetivas e que, com isso, mascara um insuportável núcleo real impossível [...]. A função da ideologia não é oferecer-nos uma via de escape de nossa realidade, mas oferecer-nos a própria realidade social como uma fuga de algum núcleo real traumático.

Temos, por um lado, uma vertente mundial de reconhecimento da diferença; de outro lado assistimos ainda a uma crescente padronização de gostos e saberes. Mesmo que travestidas de singularidades. É um paradoxo!
Constatei, em pesquisas sobre a produção do espaço universitário no Brasil ao longo do século $X X$, a idealização e consolidação de um modelo urbanístico único a nortear a produção de nossas universidades; e isso com possibilidades mínimas de ruptura (ao menos até fins do século, mas creio que até hoje). Ou seja, há uma tensão entre as possibilidades de mudança e diversidade e a cristalização de valores que as emperram.

A modernidade, nesses tempos de globalização, transforma os preceitos fundamentais da História e de forma paradoxal. Transforma o tempo em falta de tempo e, por outro lado, altera as relações temporais. Transforma o espaço em falta de espaço e, por outro, cria relações transespaciais. Cria a perplexidade do novo, que a um só tempo apóia-se e descarta a tradição. (RODRIGUES, 2001, p. 202)

Como entender processos humanos que apontam a valorização da cultura e sua diversidade convivendo com grandes intervenções urbanas e seus planejamentos estratégicos que padronizam os espaços? Como as pessoas podem se sentir estimuladas e receptivas, ou mesmo se apropriarem dos espaços ${ }^{3}$ se os mesmos se mostram indiferentes e pouco sujeitos às reais apropriações?

\section{Discutindo cultura e sua diversidade de expressões:}

Tento aqui algumas associações entre a identidade cultural do sujeito e a relação com o outro, entre a subjetividade e a ética. Ou melhor, identidade e ética creio serem faces da mesma moeda. A identidade se constrói na relação com o outro, e ética pode ser entendida como arte dos relacionamentos.

A noção de Cultura aponta a teia de significações que permeiam as práticas 
humanas. Não apenas as práticas, mas as percepções e sentimentos. Pode-se entender os diversos modos culturais como processos de sedimentação de memórias, a longo ou médio prazo, e que operam com as diferenças presentes nos sujeitos e grupos. Cultura e mediação; cultura e política. A implementação de ações no campo da cultura deve ser mediada pelos diversos agentes sociais, no entanto há que se ressaltar que a história da modernidade impingiu certa dificuldade para que essa representação social aconteça plenamente, pois como apontou o pensador português Boaventura de Souza Santos (1996) assiste-se, hoje, a uma hiperpolitização estatal e uma despolitização da vida cotidiana. Não se deveria, portanto, dissociar a ação cultural de noções ligadas à cidadania, à justiça social, à afirmação de sociedade civil e sua governança, ou mesmo à ética.

Certas concepções de desenvolvimento e de cultura ocupam lugares cada vez mais privilegiados nas tentativas de se compreender e estimular o comportamento ético da humanidade. Cultura deve ser entendida como elemento de coesão social e de fortalecimento das noções de pertencimento e de identidade; para além das dimensões institucionais dadas ao campo da Cultura, e para além das dimensões que articulam a Cultura com as representações/manifestações sociais, busca-se entendê-la enquanto formadora de subjetividades ao considerar a produção material e imaterial dos homens e grupos a partir de seus valores, comportamentos, sentimentos e desejos.

A Ética, por sua vez, deve ser entendida por sua vinculação ao pleno exercício do Eu em sua busca de felicidade e em consonância com a percepção de que esta plenitude, necessariamente, incorpora o Outro; ética como elemento estruturante de relações sociais baseadas nos níveis de confiança e coesão social interna aos grupos e destes com outros grupos e instituições. Ética como capital social, como a arte do conviver, com liberdade e responsabilidade para deliberar em conjunto com os outros sujeitos a nossa melhor forma de bem viver. A ação cultural ética envolve a circulação de ideias e a (re)formulação de práticas. Pressupõe reconhecer o outro e os comportamentos, as intenções, valores, conhecimentos que compõem o meio social, e a capacidade de interagir em outros meios.

A ideia de relações éticas e dialógicas deve nortear o âmbito das diversas relações, incluindo-se aí as relações público/privado, portanto. As diversas possibilidades de interagirmos com/nos espaços públicos, as várias possibilidades de nos apropriarmos dos lugares.

\section{Modos Culturais e Arte como necessi- dades inerentes ao Homem:}

Parto da idéia de que estamos numa área, num campo que entende as expressões artísticas e as práticas culturais (materiais e imateriais) como condições inerentes à natureza humana.

Faço eco às reflexões de Mário de Andrade (ANDRADE; ALVARENGA, 1983) quando aponta que o ser humano é movido por um somatório de três necessidades: expressão + comunicação + comoção. O sentido apontado é o de que somos movidos por necessidades que nos são intrínsecas e inerentes. A experiência vivida nos move na direção da ação/expressão, esta expressão precisa sempre assumir significação/sentido, e muitas vezes, e por necessidade mesmo, somos movidos pela necessidade de sensibilização e comoção. Vejamos um breve exemplo. O desenvolvimento humano se deu a partir de uma necessidade primeira de expressão que nos levou a emitir sons, ou a nos proteger das intempéries, ou a talhar um pedaço de madeira ou pedra. Em todas estas expressões, a carga expressiva em si necessitou assumir sentido, precisou ser entendida e 
ter uma significação. O som virou fala, nos protegemos com roupas e abrigos, o material talhado virou uma lança, enfeite ou pote para cozinhar alimentos. Mesmo supridas estas necessidades, o homem foi movido (e sempre somos) por uma necessidade de ultrapassar o meramente útil ou simbólico, e a se transformar e transformar o mundo a seu redor. O som virou também música; abrigos viraram belas arquiteturas; utensílios foram adornados com entalhes e muita expressão "não-utilitária" sempre acompanhou a produção humana.

A Cultura é entendida como expressão comunicativa/simbólica dos indivíduos e grupos, mas nos remete, também, à esfera do imaginário, do desejo. Essa dimensão maior nos coloca no campo da construção da subjetividade, e, neste, no da estreita correlação do eu com o outro (LACAN, 1978; 1985). Essa dimensão identitária nos remete, ainda, à noção de Ética. Ética entendida não como conceito de moral (este definido historicamente), mas enquanto busca de realização pessoal com e a partir do Outro. Ética como busca de felicidade, alcançada na dimensão da incorporação dos demais e na busca do bem comum. O sentido a ser reforçado aproxima as práticas culturais da ação ética e coletiva. Cultura como promoção de Sociabilidade. Cultura como fortalecimento da Identidade e da ideia de pertencimento. Ao lugar. Ao grupo.

\section{A gestão cultural e o território:}

O Brasil teve ao longo da constituição de sua rede de cidades estratégias de ocupação que marcam alguns ciclos. Embora se tenham alterado drasticamente as lógicas de ocupação territorial, muitas de nossas cidades ainda "guardam" traços de seus riscos iniciais.

As cidades fundadas no século XVI, e mesmo no XVII, foram basicamente de ocupação litorânea e voltadas à defesa do território colonial português. Assentadas em locais altos, às vezes com muralhas, contendo malhas internas irregulares e com pouca vida social. Foi assim no Rio de Janeiro, em Niterói, em Olinda, em Salvador, entre muitas outras. Com a ascensão comercial do ciclo açucareiro as principais cidades portuárias prosperam, dinamizaram suas estruturas sociais e cresceram em direção aos portos.

Ainda no século XVII, mas principalmente no século seguinte iniciou-se a ocupação interior em busca do ouro. São Paulo foi simples ponto de passagem, vindo a florescer algumas cidades mineiras e goianas. No século XIX vieram explosões econômicas importantes. A borracha fez enriquecer certas regiões do norte, e o ciclo do café definitivamente fez explodir uma larga rede de cidades, principalmente nas regiões sul-fluminense e paulista. Trouxe com ele a modernidade das redes ferroviárias e dos serviços urbanos de eletrificação e saneamento.

Foi, no entanto, ao longo do século XX que a modernização realmente impactou nossas realidades urbanas com grandes intervenções de renovação dos antigos tecidos coloniais, inicialmente no Rio de Janeiro e em São Paulo, e com o planejamento de cidades modernas: Goiânia, Brasília e Palmas expressam três desses momentos.

Nossa composição étnica por sua vez expressa, também, momentos cíclicos. Aos índios, portugueses e africanos dos primeiros séculos somaram-se importantes massas imigrantes, sobretudo européias, que cruzaram os mares em busca de oportunidades de inclusão que a industrialização vigente no "primeiro mundo" não lhes propiciou.

Que marcas territoriais e étnicas ainda se apresentam em nossas cidades? De que maneira nossos traços culturais regionais se sobrepõem à homogeneização percebida nos tempos atuais? Marcados por forte com- 
posição social excluída e sobrepujada, como estamos fortalecendo a inclusão?

Os dados censitários são bem pouco animadores. Cientistas sociais falam de abismo social. Especialistas estrangeiros adjetivam nosso nome - brasilianização como expressão de pobreza. Ainda podemos constatar bolsões de trabalho escravo no Brasil, isso sem falar dos altos índices de violência urbana e de prostituição infantil.

Diante desse quadro, como estabelecer e fortalecer as redes sociais e as sociabilidades? Como estimular e incorporar a governança e o capital social como estratégias para nossas ações? Como promover a ética como a estética de vida dos indivíduos? São desafios que devemos nos colocar constantemente...

Busquei correlacionar identidade, cultura e ética, ou seja, o sujeito se reconhece e se estrutura a partir de seus dados culturais e de sua relação com o outro. Necessariamente só haverá construção de identidade se o outro estiver em estreita interação com cada eu. Tal questão aponta para a necessidade de uma ação política presente nos sujeitos. Uma pré-disposição a incorporar o outro quer dizer a possibilidade das interações/tensões inerentes à vida pública e à participação em sociedade. Participação é um conceito que pode ser manipulado ideologicamente. Governos de diferentes matrizes políticas e coloridos ideológicos desejam a participação em seus programas. Organizações e empresas buscam a participação de clientes e usuários e/ ou de seus empregados. Há duas tendências de estabelecimento de canais de participação, ambas restritivas em sua dimensão. É comum a implementação de formas de participação segmentadas e compartimentadas em setores: saúde, educação, cultura, orçamento público etc. Outra forma agrega os grupos por territórios: associações de bairro, comunidades específicas, enfim: isola os grupos locais um dos outros.
O que estou apontando é a necessidade de participação irrestrita e mesmo inicial/ original. A necessidade dos indivíduos de viver coletivamente; a interação necessária à construção da vida pública.

\section{Produção do espaço urbano - algumas questões:}

O olhar percorre as ruas como se fossem páginas escritas: a cidade diz tudo o que você deve pensar, faz você repetir o discurso, e, enquanto você acredita estar visitando Tâmara, não faz nada além de registrar os nomes com os quais ela define a si própria e todas as suas partes. (CALVINO, 1990, p. 18)

As reflexões aqui desenvolvidas buscam explorar posicionamentos norteadores de intervenções urbanas que tomem como base o resgate do espaço enquanto local de convivência, entendendo que "revitalizar" pressupõe reviver, garantir a plena "vida" do lugar: ou seja, sua plena possibilidade de usos compartilhados pelos mais diversos agentes sociais.

Parte-se do pressuposto que o espaço urbano pleno é aquele que possibilita uma apropriação múltipla que o consolide enquanto "lugar", em direta oposição ao "não-lugar". Certeau (1998) aponta que lugar é espaço praticado, pois ligado às pessoas. Augé (1994) cunha a expressão não-lugar, designando "duas realidades complementares, porém distintas: espaços constituídos em relação a certos fins (transporte, trânsito, comércio, lazer) e a relação que os indivíduos mantém com esses espaços". Espaços marcados pela efemeridade, por apropriações rarefeitas e momentâneas. O autor considera que a dimensão do não-lugar está contida em qualquer lugar, fato que leva a que o próprio residente possa se sentir um estrangeiro em sua própria terra, no seu próprio território. 
Aponte-se, também, as reflexões de Yázigi (2001) na direção de se flagrar a "alma do lugar". O lugar incorpora o cotidiano, caracteriza a parte e o reconhecimento de que esta está em certa autonomia em relação ao todo, ao conjunto mais amplo.

Entender a produção social do espaço como produção de lugar é, então, entender essa produção a partir de sua múltipla e diversificada carga semântica: qualquer espacialidade é rica de significados, assim como é rica e diferenciada a sua apropriação pelos diferentes atores sociais. Hoje, somos levados cada vez mais a perceber as cidades por signos de significados reduzidos. A Cidade é tomada por uma ou duas imagens (sem significado e sem conteúdo), reduzida drasticamente em sua possibilidade/vocação e em sua historicidade. Os viventes de uma cidade não são mais os cidadãos políticos que geraram a polis do mundo grego, ou a urbs romana. Nem ao menos um conteúdo coletivo como apresentam as cidadelas medievais é mais encontrado na cidade pós-industrial. Baudelaire registrava o flanêur da cidade do século XIX, porém, ao que tudo indica, os usuários das cidades deste início de milênio ainda guardam um sentido assentado no século passado que transforma o cidadão num simples voyeur.

Será esta indiferença a única possibilidade que poderemos esperar atualmente das cidades? Se for, então não cabe refletir a revitalização, pois o que deu vida às cidades foi o "estar junto". Busco, ao contrário, abordar a possibilidade de dar vida aos lugares a partir dos usos coletivos neles partilhados e estimulados pelos mais variados e múltiplos motivos, inclusive o turístico e o do lazer espontâneo. Estar junto motivado por atividades culturais ou comerciais, pelo uso residencial ou institucional; enfim, estar junto. Creio que o modo de garantir e/ou estimular o livre encontro entre as pessoas é unir, o máximo possível, todos os motivos que atraiam as pessoas aos lugares coletivos.
O atual processo de globalização reforça e valoriza a diversificação, mas também homogeneíza valores. A atratividade urbana deveria se dar, a princípio, pelas singularidades que criam identidades próprias aos lugares. A produção da cidade é hoje regida por parâmetros de venda e consumo, traduzindo-se no que se denomina city-marketing ${ }^{4}$.

Um dos grandes paradoxos da produção do espaço é que ele pode levar à destruição dos próprios atrativos exercidos pelos territórios. Esse risco vem sendo reforçado, pois as sociedades contemporâneas têm se caracterizado por sociedades de consumo, regidas pelos preceitos do mercado, do lucro. Criam-se, assim, locais que não se constituem como territórios devidamente apropriados, não se constituem como "lugares". Criam-se locais artificiais, cuja infra-estrutura pode ser muito boa, mas que são locais indiferentes à região.

Lucrecia Ferrara (1999) chama de turismo dos deslocamentos virtuais a forma como os visitantes tendem a se relacionar com o espaço: de modo efêmero e superficial, atentando-se a recortes imagéticos que pouco ou nada traduzem do lugar em si. Efeito perverso da contemporaneidade, as formas de apropriação dos cidadãos com seus espaços cotidianos estão sendo marcadas, cada vez mais, pela rapidez, insegurança e superficialidade. Estamos perdendo nossa possibilidade de apropriação espacial marcada por relações interpessoais intensas e pela afetividade. A crescente mobilidade dos indivíduos no espaço e o esgarçamento da coesão social ganharam, nas palavras de Bauman (1999, p. 101), uma conotação metafórica bem oportuna: "Os turistas se movem porque acham o mundo a seu alcance (global) irresistivelmente atraente. Os vagabundos se movem porque acham o mundo a seu alcance (local) insuportavelmente inóspito".

As reflexões sobre a cidade se cruzam com diversas outras questões. A cons- 
tituição da identidade é uma das importantes. Mas se deve buscar a construção de saberes que não se pautem apenas pela memória urbana, ou pela identidade cidadã. Ao contrário de uma tendência pós-estruturalista que procura negar e desconstruir a noção de sujeito, devemos pautar-nos por reflexões que tenham como um de seus nortes a constituição da identidade (e sua possibilidade/necessidade dentro dos processos em curso na atualidade).

Assim sendo, mais do que nos pautarmos pela carga sígnica e simbólica (fruto da pós-modernidade) ou pela carga icônica e histórica de determinados bens culturais, devemos estimular a percepção e compreensão da necessidade deles se incorporarem aos nossos espaços de vivência. O fenômeno da comunicação de massa (a TV a partir dos anos 60; a internet a partir dos anos 90) tem assentado um modelo unificador junto aos indivíduos. A extensão dessa unicidade é perversa, pois aponta a construção de um consenso no qual "estar fora" aguça o sentimento de exclusão (reforçado por um projeto político-ideológico neoliberal do "deixa estar", do "fazer-se cada um por si").

A falácia tecnicista não resolve o problema, sendo necessário o resgate de uma nova ética (ou melhor, da ética em si), cabendo à cultura e à identidade uma possibilidade de reordenação do acontecer social e de resgate da sociabilidade e da urbanidade. Porém, uma lógica ordenadora contrária à dos modernistas que setorizaram nossas cidades. A arquitetura pode ter um sentido ordenador sim, mas que deve ser utilizado para estimular usos. Usos diferenciados.

\section{Produção do espaço urbano - outras questões:}

A cidade é uma construção material e, sobretudo, um espaço que resulta dos modos culturais dos que nela habitam e dela participam; isto a transforma num lugar apropriado afetivamente (ainda que sujeito a representações ideologicamente constituídas).

O espaço urbano reflete modos particularizados de vida social e sociabilidades (expressos, principalmente, nos espaços públicos das ruas e praças). É, também, e como reflexo, o espaço das contradições, conflitos e ambiguidades. Um tecido social em crise acirra o caos urbano (violência, pobreza, individualismo, isolamento, privatização da esfera pública). Os mecanismos para a reversão de tal situação precisam ser identificados através de condutas metodológicas que busquem flagrar potencialidades para uma requalificação dos espaços públicos enquanto espaços de sociabilidades múltiplas e que identifiquem estratégias para um planejamento urbano que, ao invés de reforçar experiências homogeneizadas (e ao mesmo tempo fragmentárias), possa reforçar a produção da cidade enquanto lugar antropológico permeado de sentido e memória.

Canal privilegiado de comunicação e interação, é através do espaço da cidade que potencialmente a consolidação e as trocas culturais se estabelecem. A maneira como a cidade é percebida, ou levada a ser percebida é transpassada por discursos ideológicos que parecem naturalizar práticas culturais hegemônicas e simplificadoras.

Hoje, vive-se uma realidade que enfraquece o uso da cidade enquanto experiência vivida, acarretando apropriações frágeis e efêmeras. Numa sociedade de consumo centrada em imagens e aparências, a vida urbana tende a ser uma experiência regida pelos mesmos propósitos, a cidade tratada como espetáculo.

Busca-se, através deste texto, enfocar o espaço urbano enquanto locus de apropriação coletiva. De que modos os usuários da cidade transformam o espaço em lugar de pertencimento e elos identitários? 
O cotidiano da cidade sobrevive aos processos de espetacularização? Qual o destino de nosso lugar-comum (em oposição ao lugar-nenhum)? Como conter/suavizar os processos contemporâneos de individuação que levam ao solapamento dos vínculos sociais e transformam o espaço em um não-lugar? ${ }^{5}$

Em suma, é necessário refletir sobre as condições de nossa urbanidade e nossa sociabilidade. Refletir sobre as potencialidades e dificuldades para a qualificação e vitalização dos espaços e sobre a gestão cultural do espaço da cidade (entendida pelo valor de uso dos lugares, e não pelo valor de troca onde agora a própria cidade é tomada como produto a ser consumido de maneira efêmera).

A vida pública enseja a convivência com aquele que não conheço, mas que não excluo. Em contraponto, a vida privada -como o próprio termo aponta etnologicamente- pressupõe privar, ou estar privado (e nem um nem outro pode ser uma meta satisfatória). A cidade, em seu sentido clássico, sempre apresentou uma tríplice e importante composição de espaços: o público, o econômico e o cultural; o primeiro remetendo à ágora, o segundo ao mercado e o terceiro aos adros religiosos. Três espaços coletivos que indicam não mais existir plenamente. Os motivos? Pode-se arriscar alguns: a violência urbana desvitalizando praças e calçadas; shoppings e vendas à distância a transformar radicalmente nossas vitrines de exposição de produtos. E quanto ao terceiro, serão os novos modos culturais capazes de substituir as representações coletivas de outrora?

Enfim, devemos olhar a cidade como um enigma a ser decifrado, (re)conhecer seus valores "invisíveis", enfocar paisagens urbanas como paisagens poéticas, ou seja, resgatar as poesia do urbano independente do moderno ou do antigo, e sim pelo cotidiano que nele se dá. Flagrar a cidade invisível da memória (labiríntica, ligada ao acaso, aos surtos de recomposição do passado) que se encontra superposta à cidade da razão. Uma cidade cujas singularidades encontram-se tanto no domínio da ordem (espacial) quanto da "desordem" das lembranças, nos detalhes que escapam das transformações urbanas. Recuperar nos reflexos especulares aquilo que "ilumina" os lugares comuns, os espaços cotidianos. O estar junto desinteressado e as condições físicas propícias a isso norteiam a noção de apropriação dos espaços, sobretudo os públicos e coletivos. As estratégias e objetivos a se buscar devem apontar para a identificação dos principais marcos afetivos e analisar as formas de uso e apropriação de espaços coletivos potenciais às práticas culturais e à dinâmica social da cidade; flagrar o lugar. Potencializar a memória.

Desde já um alerta: o que aqui se pretende ao falar de manutenção e resgate da memória nada tem a ver com certa tendência apontada por Andreas Huyssen (2000): "restauração historicizante de veIhos centros urbanos, cidades-museus". Não é a memória enquanto produto rentável da indústria cultural que deve ser buscada, e sim as relações mais interpessoais que o passado possibilitou e a desconstrução do não-sujeito pós-moderno - e seu não-lugar - através do resgate da identidade.

\section{GPDU “do bem”:}

Participei da banca de mestrado em Arquitetura e Urbanismo de João Batista Porto Junior em 2009 na UFF, cujo trabaIho "Refazendo o Caminho: dimensões do projeto urbano de Niemeyer para Niterói, RJ" nos faz refletir sobre os descaminhos da sociedade contemporânea. A dissertação é oportuna e necessária, e realça algumas dimensões dos GPDUs: Grandes Projetos de Desenvolvimento Urbano.

Ao se flagrar certos GPDUs, algumas questões iniciais podem ser lança- 
das: que são Grandes Projetos, não restam dúvidas; se são de Desenvolvimento, aí podemos nos questionar. Certos termos precisam ser sempre questionados. Desenvolvimento de que? A partir de que modelo? Com qual finalidade? Planejamento estratégico para quem? Com quem e por quem?

Porto Junior (2009) recorre às discussões da sociedade do espetáculo de Guy Debord (2004), estabelecendo correlações entre certas materializações da sociedade contemporânea. É neste campo que quero avançar, pois de certa forma tanto a Cultura quanto o Urbanismo são travestidos em seus sentidos essenciais e transformados em merchandising em uma sociedade que parece centrar-se somente no consumo.

A meu ver, os GPDUs normalmente são frutos dessa postura consumista. Mas serão todos eles produtores de espaços efêmeros e simplesmente espetaculares? Existe GPDU "do bem"?

Alógica de grandes cenários urbanos toma conta do planejamento atual. E valem enquanto cenário, valem por sua carga sígnica, sua imagem... Faltam em muitos dos projetos considerarem os atores que darão vida à cena; e estou falando de protagonistas e não de meros figurantes. Senão, vira só cenário. Torna-se não-lugar, local de passagem, sem enraizamento, sem vivência.

Pensar na produção dessa tipologia de espaços urbanos é como pensar na espécie de produção de arte e cultura que ainda insiste em ser apenas voltada ao "consumo" imediato. Do mesmo modo que necessitamos de ações em cultura que almejem que os indivíduos sejam fruidores, dêem efetivo uso, se apropriem, se comovam... Ser, ao invés de só parecer. Enxergar, ao invés de só olhar. Vivenciar, ao invés de só estar. Fugir do meramente eventual e efêmero.

Ao que tudo indica, os GPDUs têm a mesma lógica de uma indústria cultural voltada apenas ao consumo de massa. Ambos querem só o "espetáculo". Ambos só querem o evento que consolide a imagem, a marca. Ambos se pautam por apropriações meramente mercadológicas. Não quero ser pessimista. Quero defender uma lógica contrária.

Quero que Arte e Manifestações Culturais sejam o que são: possibilidades múltiplas de exercício de nossa possibilidade de comoção, de encantamento. Quero que os Lugares Urbanos sejam espaços de sociabilidade, de interação, de prática e vivência. $E$ não é mera questão panfletária. É como nos posicionamos no mundo. Trata-se aqui da defesa de que não façamos de nossas vidas meras representações (individuais), meras vitrines de exposição (na qual o sujeito se torna um produto, objeto), meras imagens (virtuais ou reais)... miragens...

Pelos trabalhos acadêmicos (o citado, e outros), o Caminho Niemeyer (Niterói) é um GPDU. Um grande empreendimento urbano, frutos de fortes parcerias público-privado, um exemplo do empresariamento urbano, uma marca de grife na lógica do city-marketing, um não-lugar na concepção de Augé, um espetáculo consumível na concepção de Debord, um local segregado na minha concepção; em suma: uma catástrofe. Preferiria um lugar-comum, um simples lugar. Integrado ao restante da cidade. Se almejar qualidade (?) estética é produzir esse tipo de morfologia, prefiro a simplicidade das formas urbanas vernáculas...

A lógica contemporânea que norteia as intervenções urbanas aponta para o aproveitamento das áreas centrais promovendo sua restauração em oposição à ampliação dos limites periféricos das cidades.

Diversidade gera diversidade. Intervenção com manutenção do tecido social existente e ampliação de setores e camadas sociais diferenciadas. Mesclar edificações novas com edificações antigas ou his- 
tóricas. Promover intervenções de pequeno porte e incluir a melhoria dos espaços coletivos. As quatro ideias apresentadas apontam para melhores possibilidades e resultados ao se intervir nos centros. Ou mesmo em toda e qualquer área de uma cidade.

\section{Lisboa, um caso a analisar: \\ Dois lugares... dois tempos... mas a sempre relação com o Tejo.}

Suscito um projeto, o Parque das Nações (Lisboa). Um GPDU “do bem”, assim me parece sua possibilidade e potencialidade, pois se aposta na diversidade funcional e social como garantias da requalificação. O projeto de intervenções na área portuária foi potencializado financeiramente pela Exposição Internacional de 1988, e o agora denominado Parque das Nações traz um conceito de que reabilitar pressupõe processos de ampla ressonância que ativem os mais diversificados setores/ agentes sociais. Apostou-se em qualificar a área tanto para os interesses turísticos e do grande capital, quanto para a população da cidade em toda a sua diversidade. Bem, ao menos enquanto fundamento!

Como forma de demonstrar sua capacidade de implantação de grandes intervenções urbanas, Portugal foi sede da Exposição Universal de 1998. Para tanto, planejou a recuperação/utilização de antiga área portuária às margens do Tejo. Buscou grandes arquitetos, sim. Mas não se valeu apenas destes. Planejou espaços com forte imagem e carga sígnica, mas os dedicou aos "estrangeiros" e aos "locais". E quis que o lugar guardasse sua força e sua atratibilidade para além do grande evento, atraindo turistas e população local. Planejou segundo a lógica da vivência e não do "espetáculo". Buscou-se tecer elos entre passado e presente, pois Lisboa continua sendo a tradicional cidade dos azulejos, do bacalhau e do fado. Mas é, também, a contemporânea cidade da música tecno e dos centros comerciais.

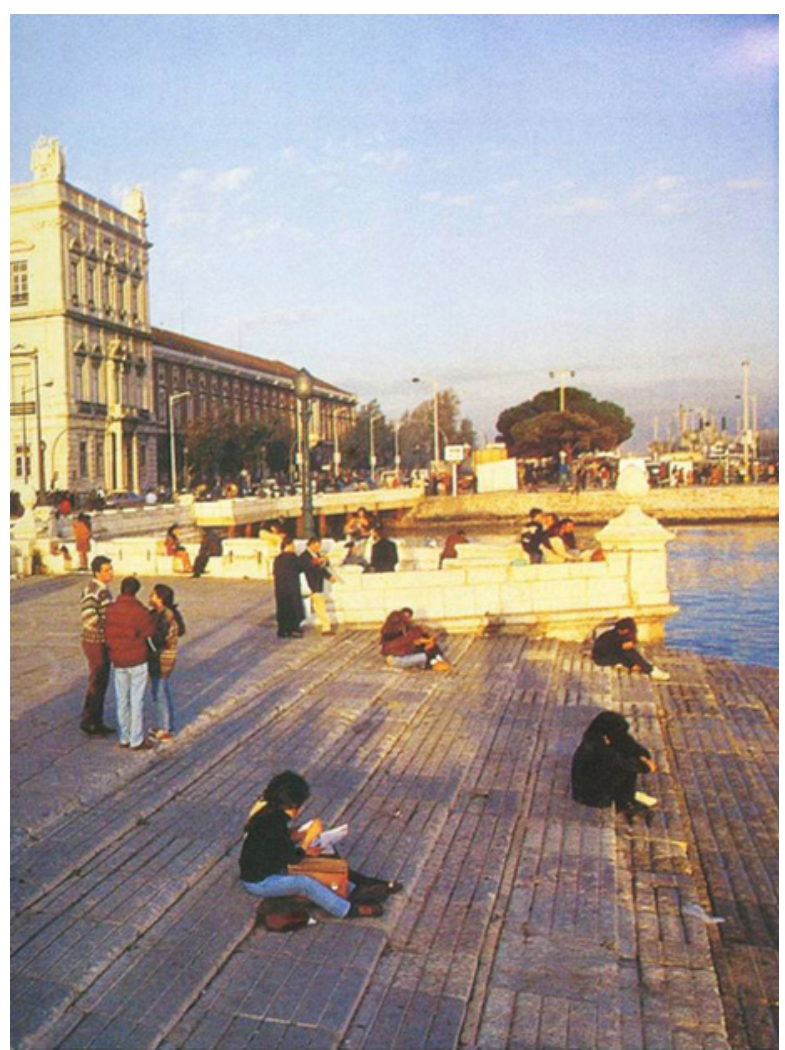

Trecho da Praça do Comércio na Baixa Pombalina ${ }^{6}$

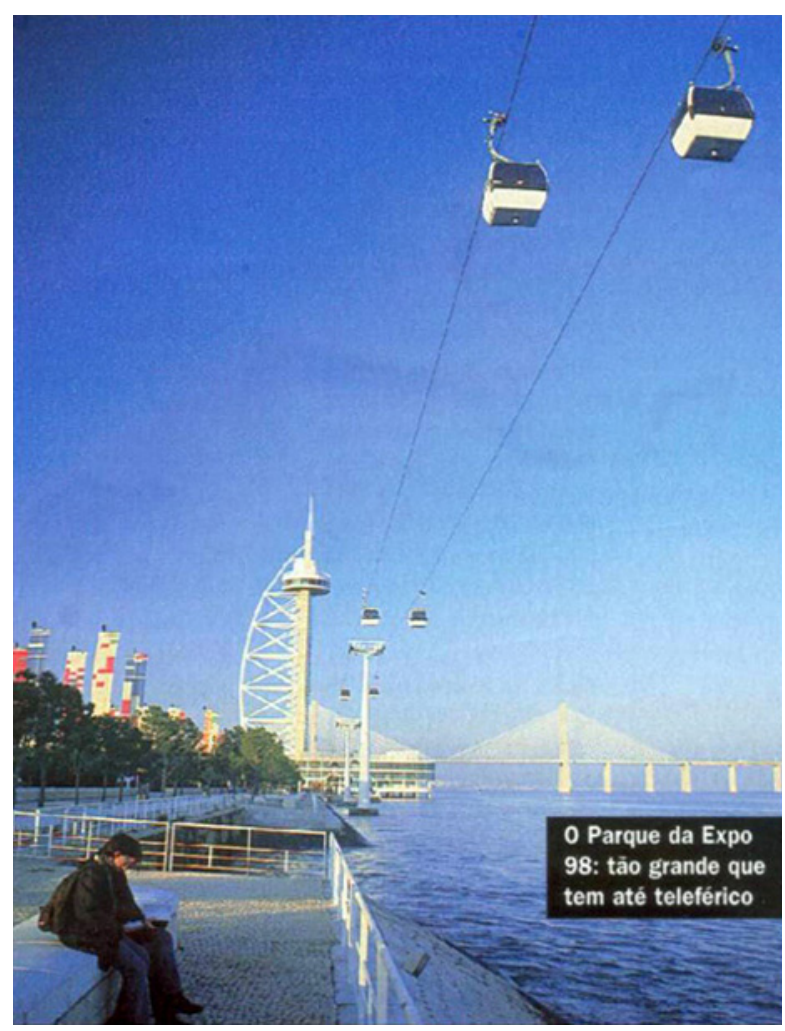

Parque das Nações ${ }^{7}$ 
A trajetória de Lisboa foi sempre marcada pela sua relação direta com o rio Tejo. Porém, no século XIX o desenvolvimento industrial e comercial determinou o crescimento da cidade para o interior, distanciando-se do Tejo. No entanto, próximo ao fim do século $X X$ a cidade torna a voltar-se para as águas. Nos anos 90 foram lançadas as bases tanto para a reabilitação dos bairros históricos, quanto para a recuperação e requalificação de toda a zona ribeirinha, agora local de lazer e convívio.

Como aparece num dos $\operatorname{sites}^{8}$ que divulgam a cidade:

Lisboa não se vê, sente-se: olhando os navios que chegam e partem do rio; calcorreando vales e colinas através das ruas estreitas e dos empedrados artísticos; observando as gentes que passam; no cheiro da sardinha assada que percorre os bairros populares durante as festas da cidade e, no fado que canta, à noite, a saudade.

Alguns textos sobre o Parque das Nações expõem parte de seus princípios:

Com efeito, a requalificação urbana, enquanto processo de intervenção social e territorial, pressupõe um conjunto de ações integradas numa determinada lógica de desenvolvimento urbano, agindo, assim, ao nível da qualidade e das condições de vida dos diversos grupos sociais -em especial, os que se encontram mais marginalizados da vida social e urbana- numa postura de democraticidade social e de generalizada apropriação individual e coletiva dos espaços em causa. Deste modo, a requalificação urbana constitui-se como um processo social e político de intervenção no território, que visa essencialmente (re)criar qualidade de vida urbana, através de uma maior eqüidade nas formas de produção (urbana), de um acentuado equilíbrio no uso e ocupação dos espaços e na própria capacidade criativa e de renovação dos agentes envolvidos nesses processos. (FERREIRA; INDOVINA, 1999)

Vê-se pelo mundo afora a sempre mesma questão: a degradação e esgotamento das áreas portuárias, tornadas obsoletas com a perda da função original. Investidas de grandes áreas construídas e de grandes vazios, as frentes de água nestes casos- tornam-se locais de pobreza e de pouca vitalidade. Esta estagnação fez, no caso de Lisboa, com que o crescimento da cidade desse as costas para o Tejo.

Buscando solucionar esse fenômeno, a gestão do território lisboeta encontrou na produção do espaço para a feira internacional a oportunidade definitiva. A zona oriental da cidade que abrigara importante função portuária tornara-se perigosa e de baixa qualidade ambiental. Indústrias petrolíferas e químicas desativadas, instalações fabris em ruínas, estoque habitacional empobrecido e acessibilidade deficiente era o quadro que caracteriza a área que recebeu o então denominado Parque das Nações. Buscou-se realinhavar as antigas relações diretas entre a área do porto e as áreas de seu entorno, fazendo com que Lisboa se voltasse orgulhosamente para o Tejo novamente.

Os impactos, tanto da intervenção urbana quanto da cultural e turística, repercutiram em mídias brasileiras:

A exposição de Lisboa, além de seu tema oficial (Os Oceanos, um Patrimônio para a Futuro), tem outro objetivo. Um dos primos pobres da União Européia, Portugal pretende aproveitar a Expo'98 para divulgar a modernização e os avanços recentes do país.

[...] Há outra novidade em relação à expo'98. Ao contrário da maioria das 
feiras mundiais, totalmente desmontadas após sua realização, a infra-estrutura da exposição de Lisboa será aproveitada após setembro. O próprio local do evento -60 hectares às margens do Tejo- foi totalmente reurbanizado durante a construção dos seis pavilhões e das demais instalações da feira. Antes tratava-se de uma região degradada e abandonada cuja poluição contaminava até o Tejo. Agora, com o rio recuperado, será integrada a um novo pólo residencial chamado Expo Urbe, com 7 mil apartamentos, escritórios e lojas ${ }^{9}$.

\section{Ou ainda:}

A belíssima estrutura de bancos, praças e jardins montada para a expo 98 também será conservada. Os turistas podem continuar subindo na torre Vasco da Gama para apreciar a paisagem, andando de teleférico de um lado a outro do parque [...]. Também não vão faltar vitrines e comprinhas. A construção do Centro Comercial Vasco da Gama, com inauguração marcada para a próxima primavera européia, será outro marco na vida do Parque das Nações. O shopping terá hipermercado, restaurantes, cinema e lojas. [...] A praça de espetáculos que recebeu alguns dos concorridos shows de MPB durante a feira, a Praça Sony, vai abrigar os mais importantes encontros musicais da capital portuguesa nos próximos tempos ${ }^{10}$.

\section{E mesmo esta outra matéria:}

A explosão de prédios modernos borbulha ainda com mais intensidade no Parque das Nações, concebido para a Expo-98, que tinha como tema Os oceanos, um patrimônio para o futuro. [...] Ao longo dos 12 quilômetros do Corredor Cultural, às margens do Tejo, atracam barcos que funcionam como bares. O espaço, arejado, é efervescente com cafés, livrarias e lojas ${ }^{11}$.
Entendo que pensar na Cultura e em seu papel no desenvolvimento de um país, região, comunidade, ou das pessoas em geral transformou-se radicalmente nas últimas décadas colocando desafios inéditos e imensos a todos aqueles que, no setor público ou no setor privado, procuram novos caminhos, soluções e funções, tanto para os tradicionais, como para os novos territórios da cultura. Se o empreendimento português atingir essa meta e se conformar como um "lugar", então temos aí um GPDU de sucesso; "do bem".

Mostra-se oportuno dar voz aos usuários. Em um blog encontramos algumas apreensões apontadas em 2010, uma década após aquele grande empreendimento. Vejamos ${ }^{12}$. "Belas fotografias de um espaço que considero desumanizado", é uma das postagens em 05/01/2010. "Não gosto muito daquilo, é 'certinho' demais", aponta outro dois dias depois. O projeto do Parque das Nações incluiu várias unidades residenciais, o que favorece a uma construção identitária, mas não é suficiente.

[...] tudo aquilo é extremamente frio e calculado, faltando aquele calor do nosso bairro, talvez porque ainda não existam gerações que ali tenham nascido para poderem dizer (Eu sou do Parque das Nações) como outros dizem com orgulho (eu sou da Mouraria ou outro), no entanto não deixarei de reconhecer que existe qualidade de vida de nível superior em relação ao resto do país. (05/01/2010)

Não gosto, nunca gostei, não me diz nada, sem significado. São mais umas séries de edifícios de apartamentos sem história, sem alma, betão e mais betão [sic]. Ficou melhor do que estava. $(07 / 01 / 2010)$

Em outro lugar de fala encontramos uma visão oposta: "O Parque das Nações é hoje um espaço vivo, dinâmico e multifun- 
cional. É a marca da Lisboa contemporânea, um local onde os lisboetas se divertem, apreciam espetáculos, passeiam, praticam desporto, fazem compras, trabalham e vivem, com qualidade e em harmonia." ${ }^{13}$ É uma fala "oficial", para atrair turistas, bem focada neste marketing. Esta fala última pode ser confrontada com outra, de 2012, que parece apontar relações de pertencimento vivenciadas pelos moradores locais que comemoram a aprovação da criação, em 01/06/12, da Freguesia do Parque das Nações, conclamando com isto uma garantia de melhor integração da área com seus residentes e usuários. Meses antes, em $15 / 03 / 12$, já vinham sendo postadas reclamações que traziam indícios de que o local fora apropriado pelos moradores.

[...] se parte do Parque das Nações ficar fora da futura freguesia, todos ficamos a perder. O Parque das Nações foi concebido e edificado como uma nova centralidade da cidade de Lisboa [...] E caso se concretize a divisão [...] teremos ruas que pertencerão às cinco autarquias. [...] Haverá crianças que deixarão de poder frequentar escolas públicas do nosso bairro [...] ${ }^{14}$

Quero enfatizar a questão da apropriação urbana e a noção de lugar antropológico por entendê-las como dimensões essenciais à sociabilidade. A possibilidade dos encontros fortuitos, e mesmo a necessidade das relações interpessoais imprevistas estruturam a vida social e reforçam a construção da identidade e da cidadania. Michel de Certeau e Milton Santos foram alguns dos teóricos que já nos ensinavam sobre esta necessidade. Retomo aqui a questão sob o olhar de Paola Jacques e as corpografias urbanas:

A partir de uma constatação da atual espetacularização das cidades contemporâneas - que resulta em cenografias urbanas - tratarei do que considero ser uma forma de resistência a esse processo: a própria experiência urbana e, em particular, a experiência corporal da cidade. Esse tipo de experiência, do corpo ordinário enquanto resistência, pode ser estimulada por uma prática que chamo de errâncias que, por sua vez, resultaria em corpografias urbanas. (JACQUES, 2007, p. 93) ${ }^{15}$

Retomo agora a questão da modernidade e o risco de uniformização e homogeneização que ela permite, mesmo travestida de novidade. Como apontou Octavio Paz (1984, p. 39): "Em todas as sociedades as gerações tercem um tela feita não só de repetições, como de variações; e em todas elas realiza-se, de um modo ou de outro, aberta ou veladamente, a 'querela dos antigos e dos modernos'. Há tantas 'modernidades' como épocas históricas." Seguindo tal raciocínio, faço eco com Slavoj Zizek (1992, p. 59) buscando "detectar, por trás da universalidade aparente, a particularidade de um interesse que destaca a falsidade da universalidade em questão: o universal, na verdade, está preso ao particular, é determinado por uma constatação histórica concreta".

O interessante em questões como estas é flagrar no próprio discurso a fantasia ideológica, os falseamentos ideológicos inconscientes. Não vou por este caminho aqui, neste momento. Apenas reforço sua potencialidade metodológica, e sigo um pouco mais com os autores. Paz (1984, p. 98) nos propõe que o "texto que é o mundo não é um texto único: cada página é a tradução e a metamorfose de outra e assim sucessivamente. O mundo é a metáfora de uma metáfora. [...] No centro da analogia há um buraco: a pluralidade de textos subentende que não há um texto original". Zizek (1996, p. 299) vai além:

A estrutura é sempre tríplice; há sempre três elementos em ação: o texto 
manifesto do sonho, o conteúdo latente do sonho, ou seu pensamento latente, e o desejo inconsciente articulado num sonho. Esse objeto, [...] consistindo inteiramente nois mecanismos do significante, [..] seu único lugar está na forma do "sonho" $[\ldots]^{16}$

O que tem de ideologia impregnada nestes vários discursos sobre 0 Parque das Nações? Os dados positivos apontados pelos moradores são construções de fato apreendidas ou são representações ideologicamente produzidas? O discurso de cunho turístico traz conexões explícitas de suas intenções pragmáticas e mercadológicas. Enfim, será mesmo possível que intervenções de grande porte como o Parque das Nações se tornem um GPDU do bem? Fica aqui uma questão a acompanhar...

\section{Bibliografia:}

ANDRADE, Mário de. ; ALVARENGA, Oneyda. Cartas. São Paulo: Livraria Duas Cidades, 1983.

AUGÉ, Marc. Não lugares: introdução a uma antropologia da supermodernidade. Campinas, SP: Papirus, 1994.

BAUMAN, Zygmunt. Globalização: as conseqüências humanas. Rio de Janeiro: Jorge Zahar, 1999.

CALVINO, Ítalo. As cidades invisíveis. São Paulo: Companhia das Letras, 1990.

CERTEAU, Michel de. A invenção do cotidiano. Petrópolis, RJ: Vozes, 1998.

DEBORD, Guy. Sociedade do espetáculo. Rio de Janeiro: Contraponto, 2004.

FERRARA, Lucrecia d'Alessio. O turismo dos deslocamentos virtuais. In: YÁZIGI, E.; CARLOS, Ana; CRUZ, R. C. (orgs.). Turismo: espaço, paisagem e cultura. São Paulo: HUCITEC, 1999. p. 15-24.

FERREIRA, Vitor Matias; INDOVINA, Francesco. (org.). A cidade da Expo'98. Lisboa: Editorial Bizâncio, 1999.
HUYSSEN, Andréas. Seduzidos pela memória: arquitetura, monumentos, mídia. Rio de Janeiro: Aeroplano, 2000.

JACQUES, Paola Berenstein. Cenografias e corpografias urbanas: espetáculo e experiência na cidade contemporânea. In: Revista Observatório Itaú Cultural / OIC. São Paulo, n.5, abr./jun. 2008. pp 47-57.

JACQUES, Paola Berenstein. Corpografias urbanas: o corpo enquanto resistência. In: Cadernos PPG-AU/FAUFBA. Salvador, ano 5, número especial, 2007, organizado por Ana clara Torres Ribeiro. pp 93-103.

LACAN, Jacques. Escritos. São Paulo: Perspectiva, 1978.

LACAN, Jacques. O Seminário - Livro 3: As Psicoses. Rio de Janeiro: Jorge Zahar Ed., 1985.

PAZ, Octavio. Os filhos do barro: do romantismo à vanguarda. Rio de Janeiro: Nova Fronteira, 1984.

PORTO JUNIOR, João Batista. Refazendo o Caminho: dimensões do projeto urbano de Niemeyer para Niterói, RJ. Niterói: Universidade Federal Fluminense, 2009. Dissertação de Mestrado em Arquitetura e Urbanismo.

RODRIGUES, Luiz Augusto F. Universidade e a fantasia moderna: a falácia de um modelo espacial único. Niterói: EdUFF, 2001.

SANTOS, Boaventura de Souza. Pela mão de Alice: o social e o político na pós-modernidade. São Paulo: Cortez, 1996.

SANTOS, Milton et al. (orgs.). Fim de século e globalização. São Paulo: HUCITEC, 1993.

YÁZIGI, Eduardo. A alma do lugar: turismo, planejamento e cotidiano. São Paulo: Contexto, 2001.

ZIZEK, Slavoj (org.). Um mapa de Ideologia. Rio de Janeiro: Contraponto, 1996.

ZIZEK, Slavoj. Eles não sabem o que fazem: o sublime objeto da ideologia. Rio de Janeiro: J. Zahar Ed., 1992.

ZIZEK, Slavoj. O mais sublime dos histéricos: Hegel com Lacan. Rio de Janeiro: J. Zahar Ed., 1991. 
1 Arquiteto/Urbanista e doutor em História Social. Professor Associado do Departamento de Arte da UFF, vinculado à graduação em Produção Cultural e à pós-graduação em Cultura e territorialidades da Universidade Federal Fluminense.

2 Podemos creditar à publicação do Relatório Nossa Diversidade Criadora, organizado por Javier Pérez de Cuellar em 1995, o marco principal das preocupações da UNESCO com a questão. A partir de então a questão cultural vai assumindo cada vez mais centralidade nas discussões internacionais, culminado em dois documentos importantes: Declaração Universal sobre a Diversidade Cultural (2001) e Convenção sobre a Proteção da Diversidade das Expressões Culturais (2005).

3 Estou, propositalmente, evitando utilizar termos como território e lugar, num claro entendimento e valorização da noção de lugar em sua acepção enquanto lugar antropológico, como será discutido mais a frente.

4 Sánchez apresenta a sucinta definição de city-marketing: "mecanismo institucional de promoção e venda da cidade como lugar de recepção/irradiação". SÁNCHEZ, Joan-Eugeni. Metropolização e modernidade. In: SANTOS, Milton et al. (orgs.). Fim de século e globalização. São Paulo: HUCITEC, 1993. p. 293-302. p. 298.

${ }^{5}$ Enquanto oposições binárias, poderíamos distinguir os termos como a seguir. Lugar é pausa e contato. É real e singular. Gera experiência. É espaço usado e vivido. Não-lugar é movimento e indiferença. É artificial e universal. Gera virtualidade. É espaço consumido e observado. A produção do lugar se efetiva a partir dos níveis de sentido que lhe atribuímos.

6 Fonte: Outflight Magazine Ponte Aérea. São Paulo, Ano 17, n. 151, s.d. Edição especial: Lisboa. p. 21 (parte da fotografia)
7 Fonte: Revista Viagem e turismo. São Paulo, Ano 6, n. 3, março/2000. p. 57.

8 http://www.cm-lisboa.pt/?idc=4, acessado em 24 de outubro de 2012.

9 Caloca Fernandes In: http://epoca.globo.com, 23/ maio/1998.

10 Célia Curto In: O Estado de S. Paulo, 27/out/1998.

11 Jornal do Brasil, 09/fev/2003.

12 As falas a seguir foram extraídas de http://extrafisico. blogspot.com.br/2010/01/hoje-lisboa-parque-das-nacoes.html, acessado em 26 de outubro de 2012.

13 www.visitlisboa.com, acessado em 26 de outubro de 2012.

14 http://freguesiadooriente.blogspot.com.br, acessado em 26 de outubro de 2012.

15 Grifo da autora. Sobre o assunto, ver também JACQUES, 2008.

16 Grifo do autor. Aqui vale nos reportarmos a Jacques Lacan (1978, p. 246): "a estrutura metonímica, indicando que é a conexão do significante com o significante, que permite a elisão pela qual o significante instala a carência do ser na relação de objeto, servindo-se do valor de remessa da significação para investi-la com o desejo visando essa carência que ele suporta. [...] a estrutura metafórica, indicando que é na substituição do significante ao significante que se produz um efeito de significação que é de poesia ou de criação, em outras palavras, de advento da significação em questão." (os negritos são meus)

\section{Contato:}

- luizaugustorodrigues@id.uff.br 